The 13th European Nutrition Conference, FENS 2019, was held at the Dublin Convention Centre, 15-18 October 2019

\title{
Fluid intake in children
}

\author{
Petr Tláskal ${ }^{1}$ and Marieta Baliková ${ }^{2}$ \\ ${ }^{1}$ Department of Medical Nutrition. Teaching hospital of Prague Motol, Prague, Czech Republic and \\ ${ }^{2}$ Department of Medical Nutrition. Teaching hospital of Prague Motol., Prague, Czech Republic
}

\begin{abstract}
Introduction

We monitored fluid intake in children. The hydration of children during morning school classes and on consumption of high-calorie drinks. Subclinical dehydration, expressed as urine osmolarity above $800 \mathrm{mmol} / \mathrm{kg}$, may result in lack of concentration and less effective listening.

\section{Population and methodology}

The population included 3,360 children aged as follows: a) 6-35 months, b) 4-6 years, c) 7-10 years d) 11-14 years. 103 children aged $10.3 \pm 1$ years were included in the study regarding body hydration. The evaluation looked at the intake of food and fluids consumed by children in full-day diet over a period of 3 to 5 days and recorded by the Nutridan program. Child hydration was assessed using three urine osmolarity samples taken at bedtime, in the morning and just before lunch break. The data was evaluated statistically against the reference values for nutrient intake of DACH.
\end{abstract}

\section{Results and discussion}

The median water intake in children was $101-103 \%$ of the Dietary Reference Values (DRV). In the b, c, d groups, the median was $81 \%-82 \%$, i.e $75 \%$ of DRV. $10 \%$ of 4 to 6 -year-old children had water intake below $49 \%$ of DRV, $10 \%$ of 7 to 10 year-olds less than $54 \%$ of DRV and $10 \%$ of 11 to 14 -year-olds less than $50 \%$ of DRV. A study regarding school children has showed that only $70 \%$ of the children drink at breakfast. $27 \%$ of the children do not consume any fluids in the morning. The mean urine osmolarity was 724 in the morning and $738 \mathrm{mmol} / \mathrm{kg}$ just before lunch. Children who had drunk less than $250 \mathrm{ml}$ of water during breakfast or less than $400 \mathrm{ml}$ of water during breakfast and second breakfast had a urine osmolarity of 910 and $850 \mathrm{mmol} / \mathrm{kg}$ respectively just before lunch. In school children, the proportion of sugars received from sweetened beverages accounted for 19.1\% of their total calorie intake. $10 \%$ of the children in groups c) and d) had this value higher than 28.2 and 30.4\% respectively. The results based on full-day diet show that sweetened drinks account for $79 \%$ of fluids consumed by children at school, whereas only for $72 \%$ at home.

The results of our studies have identified the areas where it is necessary to provide education regarding nutrition of children, to raise awareness of the importance of fluid intake, particularly focusing on the systematic approach and the choice of appropriate beverages ensuring adequate fluid intake.

\section{Conflict of Interest}

There is no conflict of interest 